\title{
Estudo da mcrobiota fúngica gastrintestinal de morcegos (Mammalia, Chiroptera) da região noroeste do estado de São Paulo: potencial zoonótico
}

\author{
Study of gastrointestinal fungal flora of bats (Mammalia, Chiroptera) of the northwest \\ region of São Paulo state: zoonotic potential
}

\section{Luciano Nery TENCATE ${ }^{1}$; Cilene Vidovix TÁPARO ${ }^{1}$; Cristiano de CARVALHO ${ }^{1}$; Sandra de Moraes Gimenes BOSCO² ${ }^{2}$ Luzia Helena QUEIROZ'; Deuvânia Carvalho da SILVA ${ }^{3}$; Silvia Helena Venturoli PERRI $^{1}$; Márcia MARINHO ${ }^{1}$}

\author{
${ }^{1}$ Departamento de Apoio, Produção e Saúde Animal da Faculdade de Medicina Veterinária da Universidade Estadual Paulista, \\ Araçatuba-SP, Brasil \\ ${ }_{2}^{2}$ Instituto de Biociências da Universidade Estadual Paulista, Botucatu-SP, Brasil \\ ${ }^{3}$ Departamento de Clínica, Cirurgia e Reprodução Animal da Universidade Estadual Paulista, Araçatuba-SP, Brasil
}

\begin{abstract}
Resumo
Os morcegos são hospedeiros de uma rica diversidade de microrganismos. Muitos trabalhos apontam uma estreita ligação entre quirópteros e fungos com potencial patogênico, principalmente por habitarem ambientes como cavernas, grutas e ocos de árvores, favoráveis à manutenção e propagação dos fungos. O objetivo do trabalho foi estudar a microbiota fúngica gastrintestinal de morcegos. Das 98 amostras pertencentes a 11 espécies de morcegos procedentes de 15 cidades estudadas, 20\% são da espécie Carollia perspicillata, 19\% Artibeus lituratus, 17\% Molossus rufus, 13\% Glossophaga soricina, 9\% Nyctinomops macrotis, 8\% Molossus molossus, 7\% Desmodus rotundus, 2\% Lasiurus ega, e 1\% Eptesicus furinalis, Myotis nigricans e Tadarida brasiliensis. O gênero Aspergillus sp. foi isolado de $29 \%$ das amostras, seguidos por 6\% Microsporum sp. e Penicillium sp., 4\% Tricophyton sp. e zigomicetos e 2\% Fusarium sp. Das espécies de leveduras, $14 \%$ foram de Rhodotorula sp., $10 \%$ Candida sp. e 2\% Cryptococcus sp., $22 \%$ dos isolados permaneceram sem identificação. Todos os 82 cultivos de vísceras foram negativos para Histoplasma capsulatum. Houve associação estatística significativa entre os resultados do cultivo microbiológico e as espécies de morcegos $(\mathrm{p}<0,05)$. Concluímos que os morcegos podem atuar como agentes veiculadores de fungos com potencial patogênico, entretanto outros trabalhos devem ser realizados a fim de estabelecer estratégias que permitam identificar os principais fatores correlacionados com o crescimento e a disseminação dos microrganismos na natureza e qual a implicação dos quirópteros no ciclo epidemiológico.
\end{abstract}

Palavras-chave: Morcegos. Leveduras. Fungos. Antropozoonoses. Estado de São Paulo.

\begin{abstract}
Bats are hosts of a rich diversity of microorganisms. Many studies indicate a close link between bats and fungi with pathogenic potential, especially for living in environments such as caves, caverns and hollow trees, favorable to the maintenance and spread of fungi. The objective was to study the gastrointestinal mycoflora of bats. Of the 98 samples belonging to 11 species of bats coming from 15 studied cities, 20\% of the species were Carollia perspicillata, 19\% Artibeus lituratus, 17\% Molossus rufus, 13\% Glossophaga soricina, 9\% Nyctinomops macrotis, 8\% Molossus molossus, 7\% Desmodus rotundus, 2\% Lasiurus ega and 1\% Eptesicus furinalis, Myotis nigricans and Tadarida brasiliensis. The genus Aspergillus sp. was isolated from $29 \%$ of the samples, followed by $6 \%$ Microsporum sp. and Penicillium sp. $4 \%$ Trichophyton sp. and zygomycetes and $2 \%$ Fusarium sp. Of yeast species, $14 \%$ were from Rhodotorula sp., $10 \%$ Candida sp. and 2\% Cryptococcus sp., 22\% of isolates remained unidentified. All 82 cultures of organs were negative for Histoplasma capsulatum. There was a statistically significant association between the results of microbiological culture and bat species $(\mathrm{p}<0.05)$. We conclude that the bats can act as disperser agents of fungi with pathogenic potential, although other studies should be performed to establish strategies to identify the main factors correlated with the growth and spread of microorganisms in nature and implication of bats in the epidemiological cycle.
\end{abstract}

Keywords: Bats. Yeasts. Molds. Anthropozoonoses. São Paulo State.

Correspondência para:

Márcia Marinho

Rua Clóvis Pestana, 793 -16050-680 - Araçatuba - SP

Telefone: +5518 3636-1382
E-mail: mmarinho@fmva.unesp.br

Recebido: 15/08/2011

Aprovado: 18/04/2012 


\section{Introdução}

A ordem Chiroptera representa cerca de um quarto da fauna de mamíferos. No Brasil ocorrem nove famílias, 64 gêneros e 167 espécies de Microchiroptera $^{1,2}$. Morcegos frugívoros são abundantes em áreas tropicais e subtropicais do Sudeste do Brasil, com importância para a Mata Atlântica ${ }^{3,4}$. Os morcegos são hospedeiros de uma rica diversidade de microrganismos. Estudos apontam uma estreita ligação entre os quirópteros e fungos com potencial patogênico, principalmente por habitarem ambientes como cavernas, grutas e ocos de árvores, favoráveis à manutenção e propagação dos fungos ${ }^{5}$.

A primeira interação entre fungos patogênicos e morcegos foi descrita por Emmons ${ }^{6}$, em 1958, após o isolamento de Histoplasma capsulatum, a partir de amostras de solo contaminadas com fezes de morcegos. Ao longo dos anos, dermatófitos, fungos filamentosos e, leveduras oportunistas e patogênicas foram isolados em amostras de fezes e de vísceras de morcegos 5,7,8, 9, 10, 11,12.

Um conjunto de fatores determina a distribuição do $H$. capsulatum no meio ambiente, geralmente havendo associação de seu isolamento com microambientes fechados, como cavernas, grutas, construções abandonadas, galinheiros, celeiros, florestas ou qualquer local onde o solo encontre-se enriquecido com excretas de aves e morcegos ${ }^{13}$. Características físicoquímicas do solo, como textura e acidez, associadas ao enriquecimento do mesmo por excretas de aves e quirópteros podem atuar como importante fonte de nitrogênio, sendo consideradas como meio de cultura adequado para o crescimento, desenvolvimento e disseminação do micro-organismo ${ }^{13,14}$. Outras espécies fúngicas com potencial patogênico, como Cryptococcus sp. podem ser isoladas a partir de excretas de quirópteros.

O objetivo geral do presente trabalho foi estudar a microbiota fúngica gastrintestinal de morcegos da região Noroeste do Estado de São Paulo. Especificamente, procurou-se verificar a veiculação de fungos com potencial zoonótico a partir de fezes de morcegos, correlacionar a inter-especificidade entre fungos e as espécies de morcegos e verificar se órgãos de morcegos constituem fontes de H. capsulatum.

\section{Material e Método}

Do período de março de 2009 a março de 2010 foram colhidos material biológico provenientes de 98 morcegos oriundos de 15 municípios da região Noroeste do Estado de São Paulo. Das 98 amostras, 83 (85\%) foram provenientes de material obtido a partir de vísceras de morcegos descongeladas e outras $15(15 \%)$ amostras provenientes de fezes frescas, de animais capturados vivos. Das 83 amostras, 38 (46\%) foram provenientes de morcegos machos e 45 (54\%) provenientes de fêmeas (Tabela 1). Todos os procedimentos empregados no decorrer do experimento foram aprovados pelo Comissão de Ética na Experimentação Animal e com autorização do Ministério do Meio Ambiente-MMA, Instituto Brasileiro do Meio Ambiente e recursos naturais renováveis IBAMA, Instituto Chico Mendes de Conservação e Biodiversidade ICMBio, processo número 12751-2.

Foram colhidas amostras de morcegos, randomicamente, através de capturas com a utilização de redes de neblina de náilon com 6 metros de comprimento por 2 metros de altura em três locais de matas: Zoológico Municipal de Araçatuba "Dr. Flávio Leite Ribeiro”, Parque Ecológico Baguaçu e Brejo da Faculdade de Medicina Veterinária da UNESP/ Campus Araçatuba - áreas de reflorestamento e de mata ciliar. Após captura e identificação dos morcegos, amostras de fezes frescas foram obtidas por processo natural, posterior à massagem abdominal, acondicionadas em frascos mantidos em caixa de isopor e submetidas ao Laboratório de Microbiologia para processamento. 
Tabela 1 - Espécies de morcegos distribuídos de acordo com a classificação da dieta, procedência e sexo - Araçatuba - SP, 2010

\begin{tabular}{|c|c|c|c|c|c|}
\hline Espécie de morcegos & Dieta & Procedência & Macho & Fêmea & Amostras \\
\hline Carollia perspicillata & Frugívoro & 1 & 9 & 11 & 20 \\
\hline Artibeus lituratus & Frugívoro & $\mathrm{b}, \mathrm{d}, \mathrm{m}, \mathrm{n}$ & 1 & 3 & $19^{*}$ \\
\hline Molossus rufus & Insetívoro & $\mathrm{a}, \mathrm{b}, \mathrm{c}, \mathrm{f}, \mathrm{g}, \mathrm{n}, \mathrm{o}$ & 11 & 6 & 17 \\
\hline Glossophaga soricina & Nectarívoro & $\mathrm{n}$ & 5 & 8 & 13 \\
\hline Nyctinomops macrotis & Insetívoro & $a, b, e, i, j, m, p$ & 3 & 6 & 9 \\
\hline Molossus molossus & Insetívoro & $\mathrm{b}, \mathrm{m}, \mathrm{o}$ & 5 & 3 & 8 \\
\hline Desmodus rotundus & Sanguívoro & 1 & 3 & 4 & 7 \\
\hline Lasiurus ega & Insetívoro & $\mathrm{j}, \mathrm{p}$ & 0 & 2 & 2 \\
\hline Eptesicus furinalis & Insetívoro & a & 1 & 0 & 1 \\
\hline Myotis nigricans & Insetívoro & o & 0 & 1 & 1 \\
\hline Tadarida brasiliensis & Insetívoro & $\mathrm{h}$ & 0 & 1 & 1 \\
\hline Total & 04 dietas & 15 cidades & 38 & 45 & 98 \\
\hline
\end{tabular}

a. Andradina, b. Araçatuba, c. Auriflama, d. Barbosa, e. Bilac, f. Birigui, g. Braúna, h. Brejo Alegre, i. Castilho, j. Coroados, 1. Guararapes, m. Ilha solteira, n. Mirandópolis, o. Penápolis, p. Pereira Barreto. ${ }^{\star} 15$ amostras em forma de pool de fezes

Quirópteros mortos e congelados, com diagnóstico prévio negativo para Raiva foram gentilmente cedidos pelos Laboratórios de Quirópteros e de Raiva da Faculdade de Medicina Veterinária da UNESP/ Campus de Araçatuba. Após o descongelamento, para a retirada das vísceras e fezes, os morcegos foram introduzidos em uma capela de fluxo laminar, fixados pelos membros superiores e inferiores em suporte de isopor com agulhas e, posteriormente à assepsia da parede abdominal prosseguiu-se com a abertura da mesma com subsequente exposição e retirada de intestino, fígado e baço. Os órgãos individualmente processados foram macerados, sob condições estéreis, em solução salina adicionada de $100 \mu \mathrm{g} / \mathrm{mL}$ de cloranfenicol e submetidos à agitação vigorosa em Vórtex por 2 minutos.Posteriormente, a solução, permaneceu em repouso por um período de 60 minutos, de onde foram colhidas amostras e imediatamente semeadas nos meios de cultura Ágar Sabouraud dextrose a $4 \%$ e Brain heart infusion (BHI) acrescido de 5\% de sangue desfibrinado de carneiro, e enriquecido com $10 \mathrm{~g} / \mathrm{L}$ de glicose e 1 $\mathrm{g} / \mathrm{L}$ de L-cisteína ${ }^{15}$. As culturas foram incubados a $25^{\circ}$ e $37^{\circ} \mathrm{C}$, respectivamente, por um período de 15 a 20 dias, podendo estender -se até 40 dias $^{16}$. Após o período de sete dias de incubação, foram identificados fungos filamentosos com características macro e micromorfológicos classificados de acordo com, Larone ${ }^{16}$, utilizando-se, a coloração de lactofenol azul de algodão. As colônias com crescimento leveduriforme foram submetidas a coloração de tinta nanquim, e com base na presença de cápsula, prosseguiu-se com testes fisiológicos como: produção de urease, termotolerância a $35^{\circ} \mathrm{C}$, sensibilidade a cicloheximida e atividade enzimática da fenoloxidase, conforme descrito por Lugarini ${ }^{17}$.

As colônias de fungos com potencial zoonótico foram submetidas à caracterização molecular para a identificação da espécie, por meio da reação em cadeia da polimerases (PCR). Para a extração do DNA uma porção do isolado de levedura (obtida com a utilização de alça bacteriológica) foi suspendida em tubo de 1,5 mL contendo $500 \mu \mathrm{L}$ de solução de TrisEDTA (10 mM Tris, $1 \mathrm{mM}$ EDTA). Em seguida, a mistura foi aquecida a $95^{\circ} \mathrm{C}$ por 3 minutos e congelada em nitrogênio líquido por 1 minuto, cinco vezes, com uma centrifugação final a $16.100 \mathrm{~g}$ por um período de cinco minutos. 
Foi utilizado um par de primers específicos para região do espaçador transcrito interno (ITS-2) de leveduras $^{18}$ com as respectivas sequências: GTGAATCATCGAATCTTTGAAC (senso) e TCCTCCGCTTATTGATATGC (anti-senso) (Invitrogen, São Paulo, Brasil). A reação ocorreu em 35 ciclos, sendo $94^{\circ} \mathrm{C} / 2$ minutos $(1 \mathrm{X}), 94^{\circ} \mathrm{C} / 45$ segundos, $61^{\circ} \mathrm{C} / 1$ minuto e $72^{\circ} \mathrm{C} / 2$ minutos (35X) e uma extensão final a $72^{\circ} \mathrm{C}$ por 10 minutos.

$\mathrm{O}$ fragmento resultante da PCR para a região ITS-2 foi purificado (QIAquick Gel Extraction Kit Qiagen $^{\varpi}$ ) e submetido à sequenciamento utilizandose o ABI Prism ${ }^{\varpi}$ Dye Terminator Cicling Sequence Kit (Applied Biosystems ${ }^{\mathrm{TM}}$ ). As reações de sequenciamento foram realizadas nas duas direções, utilizando-se os mesmos primers da PCR. Para análise do sequenciamento da amostra foi utilizado o software BioEdit Sequence Alignment Editor versão 5.0.6. As sequências obtidas foram então comparadas pela ferramenta BLASTn junto às bases de dados do NCBI/Genbank ${ }^{19}$.
A associação dos resultados microbiológicos com as espécies de morcegos foram analisadas pelo teste para variáveis não paramétricas do teste Qui-Quadrado utilizando-se o software GraphPad Prism (versão 5.03 para Windows, GraphPad Software, San Diego California USA) sendo que o valor de $\mathrm{p} \leq 0,05$ foi considerado estatisticamente significativo.

\section{Resultados e Discussão}

Foram colhidas 98 amostras colhidas pertenceram a 11 espécies de morcegos, naturalmente distribuídas por toda a região Noroeste do Estado de São Paulo (Figura 1).

Com relação aos hábitos alimentares houve predomínio de espécies frugívoras (40\%), como Artibeus lituratus e Carollia perspicillata, e insetívoras (40\%), entre Molossus rufus, Molossus molossus, Nyctinomops macrotis, Lasiurus ega, Tadarida brasiliensis, Myotis nigricans e Eptesicus furinalis e, em menor número se encontram os animais de hábitos nectarívoros (13\%)

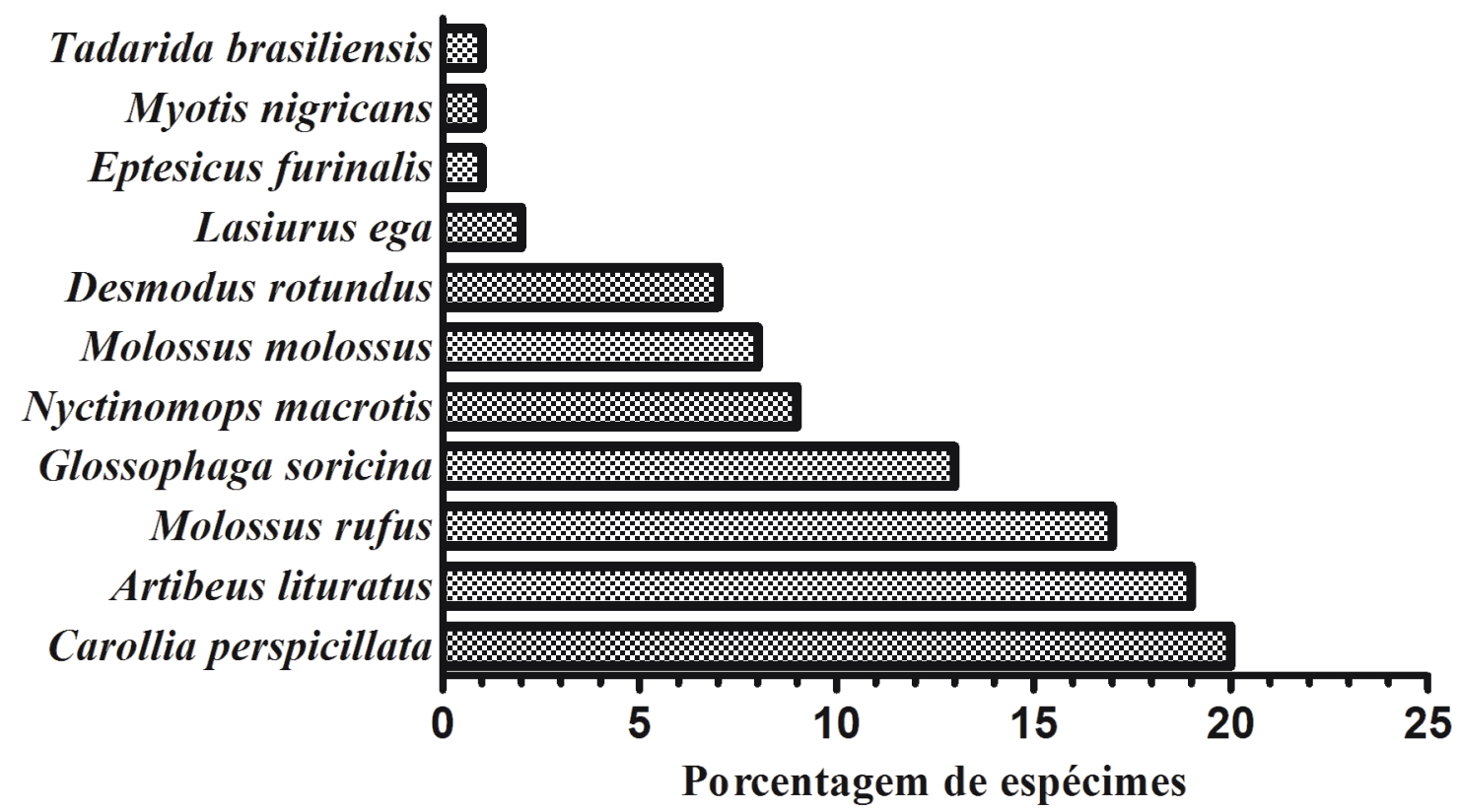

Figura 1 - Resultados expressos em porcentagem de acordo com as espécies de morcegos encontradas - Araçatuba - SP, 2010 
e sanguívoros (7\%), Glossophaga soricina e Desmodus rotundus, respectivamente.

Em nosso estudo a espécie de morcego de maior ocorrência foi C. perspicillata com 20 (20\%) exemplares, sendo a mais predominante na região Noroeste do Estado de São Paulo, corroborando com os achados de Pedro e Taddei ${ }^{4}$. Porém, em capturas realizadas no município de Araçatuba no ano de 2009 houve grande ocorrência de A. lituratus, $72 \%$ dos espécimes capturados (dados não publicados), espécie frugívora, previamente descrita como abundante nas regiões da Mata Atlântica ${ }^{3}$. Morcegos insetívoros como molossídeos e vespertilionídeos são hábeis em desviar de redes de neblina ${ }^{4}$, o que justifica a ausência de morcegos insetívoros em capturas e a prevalência de frugívoros. A análise da ficha de encaminhamento do Laboratório de Raiva dos espécimes, verificou-se notável a presença de morcegos encontrados em áreas urbanas e domiciliares das cidades da região estudada, aumentando significativamente, o contato interespécie com o homem e animais, podendo acarretar sérios prejuízos à saúde pública. M. molossus são sabidamente encontrados em áreas urbanas, principalmente em forros de casas, construções e em ocos de árvores ${ }^{1}$.
Do total de 98 amostras de excretas e vísceras de morcegos submetidas aos cultivos microbiológicos no presente trabalho, 40 (41\%) foram positivas para pelo menos um gênero de fungo. Dos 49 fungos isolados das amostras positivas no cultivo microbiológico 25 (51\%) corresponderam a fungos de cinco gêneros, Aspergillus sp., Fusarium sp., Microsporum sp., Tricophyton sp. e Penicillium sp.; e um da classe Zygomycota, 13 (26,5\%); de leveduras dos gêneros Candida sp., Cryptococcus sp. e Rhodotorula sp. e 11 (22\%) não identificados, sendo $10(20,4 \%)$ isolados de fungos miceliais e um $(4,9 \%)$ leveduras.

Das espécies de fungos isoladas a partir do cultivo de amostras de morcegos da região Noroeste do Estado de São Paulo (Tabela 2), o gênero recuperado em maior número foi Aspergillus sp., totalizando 14 (29\%) das amostras positivas, corroborando com os dados observados por Rezende, Duarte e Filiú ${ }^{5}$, que também apresentaram dominância de Aspergillus sp. (79,16\%) nas amostras de fezes de morcegos. Entre outros fungos miceliais encontrados três amostras (6\%) foram identificadas como Penicillium sp., duas (4\%) como zigomicetos e uma (2\%) como Fusarium sp., fungos também observados no trabalho do autor supracitado.

Tabela 2 - Espécies de fungos isolados a partir de fezes de morcegos - Araçatuba - SP, 2010

\begin{tabular}{|c|c|c|c|c|c|c|c|c|c|}
\hline $\begin{array}{l}\text { Espécies de } \\
\text { Chiroptera }\end{array}$ & Aspergillus & Candida & Cryptococcus & Fusarium & Dermatophytos & Penicillium & Rhodotorula & Zigomiceto & $N D$ \\
\hline A. lituratus & 5 & 0 & 1 & 0 & 0 & 0 & 2 & 0 & 6 \\
\hline C. perspicillata & 3 & 0 & 0 & 0 & 2 & 3 & 3 & 0 & 2 \\
\hline D. rotundus & 3 & 2 & 0 & 0 & 0 & 0 & 0 & 1 & 0 \\
\hline E. furinalis & 1 & 0 & 0 & 0 & 0 & 0 & 0 & 0 & 0 \\
\hline G. soricina & 2 & 0 & 0 & 0 & 0 & 0 & 0 & 0 & 0 \\
\hline L. ega & 0 & 2 & 0 & 0 & 1 & 0 & 0 & 0 & 0 \\
\hline M. molossus & 0 & 1 & 0 & 0 & 0 & 0 & 0 & 0 & 0 \\
\hline M. rufus & 0 & 0 & 0 & 1 & 2 & 0 & 2 & 1 & 1 \\
\hline M. nigricans & 0 & 0 & 0 & 0 & 0 & 0 & 0 & 0 & 0 \\
\hline N. macrotis & 0 & 0 & 0 & 0 & 0 & 0 & 0 & 0 & 2 \\
\hline T. brasiliensis & 0 & 0 & 0 & 0 & 0 & 0 & 0 & 0 & 0 \\
\hline Total & 14 & 5 & 1 & 1 & 5 & 3 & 7 & 2 & 11 \\
\hline
\end{tabular}

ND = não identificados 
No presente estudo, fungos dermatófitos como $\mathrm{Mi}$ crosporum sp. e Tricophyton sp. foram recuperados em cinco $(10,2 \%)$ amostras de morcegos, corroborando com os resultados de Kajihiro ${ }^{9}$ (1965) que isolou 22,4\% de M. gypseum, 5\% de T. mentagrophytes, 3\% de T. rubrum e $0,5 \%$ de $T$. terrestre, a partir de fezes de morcegos de cavernas da região Sudeste do Novo México.

Dos 14 isolados de leveduras $(28,57 \%$ do total de amostras) que foram submetidas ao teste da enzima urease, oito $(57,14 \%)$ apresentaram resultado positivo. Para o teste de termotolerância, 13 (92,86\%) amostras tiveram crescimento exponencial em estufa a $37^{\circ} \mathrm{C}$ por no máximo sete dias. Já para o teste da enzima fenoloxidase, apenas uma amostra $(7,14 \%)$ foi positiva à prova, sendo considerada pertencente ao gênero Cryptococcus sp. e encaminhada para caracterização molecular. As demais sete amostras (50\%) foram identificadas como pertencentes ao gênero Rhodotorula sp., enquanto que outras cinco amostras equivalentes a $35,71 \%$ foram compatíveis com o gênero Candida sp., semelhantemente aos resultados apresentados por Mok, Luizão e Silva ${ }^{10}$, que isolaram espécies de Candida sp. de $66 \%$ de amostras provenientes de fígado, baço e pulmão de morcegos. A presença de microorganismo com potencial patogênico em excretas de morcego sugere um papel importante do hospedeiro na ecoepidemiologia das enfermidades, principalmente pela viabilidade prolongada dos patógenos em fezes no ambiente, podendo ser carreada pelo vento para outras excretas não contaminadas. Nos isolados, não foi verificado a presença de H. capsulatum, diferentemente dos resultados expressos por Mok, Luizão e Silva ${ }^{10}$ e Rezende, Duarte e Filiú ${ }^{5}$, que verificaram a presença deste micro-organismo a partir de material biológico de quirópteros. Após o primeiro isolamento de H. capsulatum, por Emmons ${ }^{6} \mathrm{em}$ 1958, a partir de amostras de solo contaminadas com excretas de morcego, outros autores ao longo dos anos também reportaram sua presença, especialmente em cavernas, habitat comum dos morcegos ${ }^{5}$. Recente- mente, Galvão Dias et al..$^{20}$ isolaram 87 (3,6\%) amostras de $H$. capsulatum provenientes de órgãos macerados de morcegos, especificamente das espécies $M$. molossus (74), N. macrotis (10), T. brasiliensis (1), M. rufus (1) e Eumops glaucinus (1), todos insectívoros e provenientes de áreas urbana do estado de São Paulo. De acordo com Rezende, Duarte e Filiú ${ }^{5}$ há uma estreita ligação entre H. capsulatum e Cryptococcus neoformans a um determinado ambiente como: cavernas, casas abandonadas, ocos de arvores, estando a prevalência do patógeno diretamente relacionada à temperatura, umidade e ao $\mathrm{pH}$ do ambiente ${ }^{21,22}$. A região noroeste do estado de São Paulo caracteriza-se por clima quente e seco podendo tal fato, justificar a negatividade do isolamento de H. capsulatum em nossas amostras, uma vez que esses fatores acarretariam uma diminuição da viabilidade do patógeno no ambiente.

A caracterização molecular da região ITS-2 da amostra de Cryptococcus sp. do nosso experimento, não nos permitiu diferir entre as espécies de C. albidus, C. albidosimilis, C. diffluens e C. liquefaciens (sequencias indexadas no GenBank sob números de acessos AF219002, EU149787, AF145330 e AF444348, respectivamente), uma vez que as mesmas apresentaram $100 \%$ de semelhança gênica. $\mathrm{Na}$ análise dos nossos resultados verificamos a possibilidade da amostra de Cryptococcus sp. pertencer à espécie C. albidus, já que esta espécie tem sido isolada a partir de amostras de morcegos ${ }^{12}$.

De acordo com a análise estatística do teste Quiquadrado houve associação estatística significativa (p $=0,0393$ ) entre os resultados do cultivo microbiológico com as espécies de morcegos. Entretanto, os resultados dos fungos isolados foram variados com relação às espécies de morcegos, não sendo observada nenhuma associação específica entre fungo e morcego.

\section{Conclusões}

A análise dos resultados permite concluir que a microbiota fúngica gastrintestinal de morcegos da 
região constituí-se por fungos com potencial patogênico como Cryptococcus sp., Microsporum sp. e Tricophyton sp.; oportunistas como Aspergillus sp., Candida sp., Fusarium sp. e Penicillium sp., e ambientais como, Rhodotorula sp. e zigomicetos. Nossos resultados não permitiram-nos fazer uma associação entre espécies de morcegos e fungos isolados, negando a existência da relação interespecífica entre os mesmos. Novos trabalhos devem ser desenvolvidos a fim de co-

\section{Referências}

1. REIS, N. R.; PERACCHI, A. L.; PEDRO, W. A.; LIMA, I. P. Morcegos do Brasil. Londrina: EDUEL, 2007. 253 p.

2. SIMMONS N. B. Order Chiroptera. In: WILSON, D. E.; REEDER, D. M. Mammal species of the world: a taxonomic and geographic reference. 3. ed. Washington D.C.: Smithsonian Institution Press, 2005. p. 312-529.

3. PASSOS, F. C.; SILVA, W. R.; PEDRO, W. A.; BONIN, M. R. Frugivoria em morcegos (Mammalia, Chiroptera) no Parque Estadual Intervales, sudeste do Brasil. Revista Brasileira de Zoologia, v. 20, p. 511-517, 2003.

4. PEDRO, W. A.; TADDEI, V.A. Taxonomic assemblage of bats from Panga Reserve, southeastern Brazil: abundance patterns and trophic relations in the Phyllostomidae (Chiroptera). Boletim do Museu de Biologia Mello Leitão, Nova Série, v. 6, p. 3-21, 1997.

5. REZENDE, C.C.; DUARTE, D. C.; FILIÚ, W. F. O. Pesquisa de Cryptococcus neoformans e Histoplasma capsulatum na gruta lago azul, Bonito - MS. In: CONGRESSO DE ESPELEOLOGIA, 27, 2003. Januária. Anais... Januária-MG: Sociedade Brasileira de Espeleologia, 2003. CD-ROM.

6. EMMONS, C. W. Association of bats with histoplasmosis. Public Health Reports, v. 73, p. 590-595, 1958.

7.GROSE, E.; TAMSITT, J. R. Paracoccidioides brasiliensis recovered from the intestinal tract of three bats (Artibeus lituratus) in Colômbia. Sabouraudia, v. 4, p. 124-125, 1965.

8. GROSE, E.; MARINKELLE, C. J.; STREIGEL, C. The use of tissue cultures in the identification of Cryptococcus neoformans isolated from colombian bats. Medical Mycology, v. 6, p. 127$132,1968$.

9. KAJIHIRO, E. S. Occurrence of dermatophytes in fresh bat guano. Applied Microbiology, v. 13, p. 720-724, 1965.

10.MOK, W. Y.; LUIZÃO, R. C.; SILVA, M. S. B. Isolation of fungi from bats of the Amazon basin. Applied and Environmental Microbiology, v. 44, p. 570-575, 1982.

11.SUGITA, T.; KIKUCHI, K.; MAKIMURA, K.; URATA, K.; SOMEYA, T.; KAMEI, K.; NIMI, M.; UEHARA, Y. Trichosporon species isolated from guano samples obtained from batinhabited caves in Japan. Applied and Environmental Microbiology, v. 71, p. 7626-7629, 2005.

12.ULLOA, M.; LAPPE, P.; AGUILAR, S.; PARK, H.; PÉREZMEJÍA, A.; TORIELLO, C.; TAYLOR, M. L. Contribution to the study of mycobiota present in the natural habitats of nhecer o potencial patogênico de fungos veiculados por morcegos.

\section{Agradecimento}

Os autores agradecem à colaboração do Prof. Dr. Wagner André Pedro na identificação dos espécimes de morcegos envolvidos no estudo bem como ao Prof. Dr. Marcelo Vasconcelos Meireles pelo apoio na caracterização molecular.

Histoplasma capsulatum: an integrative study in Guerrero, Mexico. Anales del Innstituto de Biología. Serie Botánica, v. 77, p. 153-168, 2006.

13.CANO, M. V. C.; HAJJEH, R. A. The epidemiology of histoplasmosis: a review. Seminars in Respiratory Infections, v. 16, n. 2, p. 109-118, 2001.

14.KWON-CHUNG, K. J.; BENNETT, J. E. Histoplasmosis. In: KWON-CHUNG, K. J.; BENNETT, J. E. (Ed.) Medical Micology. Philadelphia: Lea \& Febiger, 1992. p.464-513.

15.ZANCOPÉ-OLIVEIRA, R. M.; WANKE, B. Isolamento do Histoplasma capsulatum de animais silvestres no município do Rio de Janeiro .Cadernos de Saúde Pública, v. 2, p. 42-53, 1986.

16. LARONE, D. H. Medically important fungi a guide to identification. 2. ed. Washington, DC: 1987.230 p.

17.LUGARINI, C. Isolamento de Cryptococcus neoformans a partir de excretas de passeriformes e psittaciformes no Estado do Paraná. 2007. 90 f. Dissertação (Mestrado) Universidade Federal do Paraná, Curitiba, Paraná, 2007.

18.DE BAERE, T.; CLAEYS, G.; SWINE, D.; MASSONET, C.; VERSCHRAEGEN, G.; MUYLAERT, A.; VANEECHOUTTE, M. Identification of cultured isolates of clinically important yeast species using fluorescent fragment length analysis of the amplified internally transcribed rRNA spacer 2 region. BMC Microbiology, v. 2, p. 21-28, 2002.

19. NCBI. Gent Bank Overview. Disponível em: http://www.ncbi. nlm.nih.gov/genbank/. Acesso em: 30 abr. 2012.

20. GALVÃO DIAS, M. A.; OLIVEIRA, R. M.; GIUDICE, M. C.; NETTO, H. M.; GRIGORIO, I. M.; ROSA, A. R.; AMORIM, J.; NOSANCHUK, J. D.; TRAVASSOS, L. R.; TABORDA, C. P. Isolation of Histoplasma capsulatum from bats in the urban área of São Paulo State, Brazil. Epidemiology and Infection, v. 139, n. 10, p. 1642-1644, 2011.

21. FILIÚ, W. O. Cryptococcus neoformans de origem saprofítica da cidade de Campo Grande-MS. 2000. 69 p. Dissertação (Mestrado em Biologia Parasitária) - Fundação Oswaldo Cruz, Rio de Janeiro, Rio de Janeiro, 2000

22.ZANCOPÉ-OLIVEIRA, R. M.; WANKE, B. Distribuição das fontes de infecção do Histoplasma capsulatum var. capsulatum em Rio da Prata, Município do Rio de Janeiro. Revista do Instituto de Medicina Tropical de São Paulo, v. 29, n. 4, p. 243-250, 1987. 